\title{
The role of education and migration background in explaining differences in folic acid supplementation intake in pregnancy: results from a German birth cohort study
}

\author{
Céline Miani 1,* (1), Angelique Ludwig 1,2, Ina-Merle Doyle ${ }^{1,3}$, Jürgen Breckenkamp', \\ Chantal Hoeller-Holtrichter ${ }^{1}$, Jacob Spallek ${ }^{4}$ and Oliver Razum ${ }^{1}$ \\ 'Department of Epidemiology and International Public Health, School of Public Health, Bielefeld University, Bielefeld, \\ Germany: ${ }^{2}$ Center for Innovation in Health Economics (ZIG OWL), Bielefeld, Germany: ${ }^{3}$ Institute for General Practice, \\ Hannover Medical School, Hannover, Germany: ${ }^{4}$ Department of Public Health, Institute for Health, Brandenburg \\ University of Technology Cottbus-Senftenberg, Senftenberg, Germany
}

Submitted 11 December 2020: Final revision received 21 July 2021: Accepted 12 August 2021: First published online 23 August 2021

\begin{abstract}
Objective: Official German recommendations advise women to start taking folic acid supplementation (FAS) before conception and continue during the first pregnancy trimester to lower the risk of birth defects. Women from lower socioeconomic background and ethnic minorities tend to be less likely to take FAS in other European countries. As little is known about the determinants of FAS in Germany, we aimed to investigate the association between FAS and formal education and migration background, adjusting for demographic factors.

Design: We used data (2013-2016) on nutrition and socio-economic and migration background from the baseline questionnaire of the BaBi cohort study. We performed multivariate regressions and mediation analyses.

Setting: Bielefeld, Germany.

Participants: Nine-hundred forty-seven women (pregnant or who had given birth in the past 2 months).

Results: $16.7 \%$ of the participants (158/947) did not use FAS. Migration-related variables (e.g. language, length of stay) were not associated with FAS in the adjusted models. FAS was lower in women with lower level of formal education and in unplanned pregnancies. Reasons given by women for not taking FAS were unplanned pregnancy and lack of knowledge of FAS.

Conclusions: Health practitioners may be inclined to see migrant women as an inherently at-risk group for failed intake of FAS. However, it is primarily women who did not plan their pregnancy, and women of lower formal education level, who are at risk. Different public health strategies to counter low supplementation rates should be supported, those addressing the social determinants of health (i.e. education) and those more focused on family planning.
\end{abstract}

Keywords
Folic acid supplementation
Pregnancy
Birth cohort
Education
Germany
Migration

The German National Consensus Recommendations on Nutrition and Lifestyle in pregnancy advises women to start taking acid folic supplement as soon as they intend to conceive and to continue supplementation during the first 12 weeks of pregnancy to lower risks of birth defects ${ }^{(1)}$. Folate deficiency has indeed been associated with neural tube defects ${ }^{(2)}$, and without supplementation, most pregnant women in Germany do not meet the recommended level of folate through their regular diet ${ }^{(3)}$. It is not clear if folic acid supplement should be taken throughout pregnancy, but evidence with regard to the benefits of supplementation during the months before pregnancy and the first trimester is robust ${ }^{(1)}$.

Despite clear benefits and recommendations, not all women take folic acid supplementation (FAS) during the periconceptional phase in Germany, a country with higher neural tube defect rates than other Western European countries $^{(4)}$. A couple of studies have tried to estimate the rate of FAS before and during pregnancy in Germany: in 2003, among 3210 women surveyed, $73.8 \%$ took folic acid supplement during pregnancy and $31.7 \%$ before pregnancy ${ }^{(5)}$. A smaller but more recent study conducted in 
2009 in the Munich area found that $85.6 \%$ of pregnant women had taken supplement during or before their pregnancy (and $33.7 \%$ before) ${ }^{(6)}$. Even more recently, a crosssectional study conducted in rural Germany estimated the prevalence of FAS during the whole of the periconceptional phase at $41.5 \%{ }^{(7)}$.

The literature consistently shows that one of the main predictors of not taking acid folic supplementation is having not planned the pregnancy ${ }^{(8)}$, which is logical since acid folic supplementation is particularly recommended before conception and in the first trimester of pregnancy, phases of pregnancy that unexpectedly pregnant women would not identify as such. The international evidence also highlights variation in FAS according to socio-demographic characteristics. Among them are formal education, migration background and ethnicity. There is, for example, a body of evidence showing that women from lower socio-economic background are less likely to take supplements before or during pregnancy ${ }^{(9-15)}$. Belonging to an ethnic minority has also been consistently associated with low intake of FAS. Several studies have shown that nonCaucasian women in Europe tend to have lower FAS than Caucasian women ${ }^{(8,11,16-18)}$. More specifically, evidence from the Netherlands ${ }^{(19)}$, Belgium ${ }^{(11)}$ and Norway ${ }^{(9)}$ demonstrated that women from Turkey or the Middle East are less likely to take FAS than the native population. Although lower levels of formal education among ethnic minorities seem to play a role in lower intake levels, the role of their migration background is less well known. Factors related to migration status rather than ethnicity may include language barrier ${ }^{(17)}$ or acculturation ${ }^{(20)}$. In order to support effective antenatal services and targeted awareness campaigns, it is crucial to understand exactly which mechanisms are at play in explaining lower intake among certain population subgroups in a given context. This includes, beyond ethnicity or region of origin, other aspects of the migration status (e.g. first- $v$. second-generation women, length of stay in the country of reception) and different measures of acquaintance with the language and culture of the country of reception (e.g. language proficiency, communication issues). Our objective here is twofold: first look for the first time in Germany at the consumption of FAS among subgroups with different migration backgrounds and then try to understand differences in consumption, exploring the potential determinants of FAS - in particular, the role of migration-related factors, education and the fact of having or not a planned pregnancy.

\section{Methods}

We used data from a prospective cohort study which was designed to include a high proportion of women with a migration background, the BaBi cohort study. In 20132016, we enrolled and interviewed women in the perinatal period (in the last pregnancy trimester or up to 8 weeks postpartum) in Bielefeld, Germany, resulting in a cohort of 977 women and 989 children (6 pairs of twins). In the baseline survey, we collected data on nutrition during pregnancy (including on FAS), health, and socio-economic and migration background. We offered to conduct interviews in German, Turkish, Polish or English in an effort to accommodate the needs of the participants with a migration background and to include women representing some of the largest groups of migrants in Bielefeld ${ }^{(21)}$. Trained research assistants collected the data through face-to-face Computer-Assisted Personal Interviews (CAPI). More details on the methods and data collected can be found elsewhere ${ }^{(22)}$. Informed written consent from all the participants was obtained.

\section{Variables of interest}

All the variables of interest were collected during the baseline CAPI of the cohort study. Women were interviewed either in their last pregnancy trimester or postpartum, up to 8 weeks after giving birth.

Our outcome of interest, intake of FAS is measured as an answer to two questions:

1. 'Did you take folic acid supplements before or at any point during your pregnancy (prompt: folic acid only in the form of a dose of minimum 400 microgram or in combination with other supplements)?';

2. 'If yes, when did you start taking folic acid supplements?' (a. before the pregnancy/conception; b. at the beginning of the pregnancy (pregnancy week 1 to 13); c. later in the pregnancy (pregnancy week 14 or beyond)).

Those two questions were preceded by a more generic question on supplements during pregnancy ('have you taken during this pregnancy nutritional supplements e.g. vitamins or minerals under the form of capsules, tablets, powder or similar?') and asked to all participants, even if they had answered 'no' to the generic question. The data make it possible to distinguish between starting to take folic acid supplements before pregnancy, during the first trimester of pregnancy or later. As recommendations and benefits are clear regarding early FAS initiation only, we classified those who started FAS before pregnancy or in the first trimester as FAS $=1$. Other participants (those who started FAS after week 13 or never took FAS) were coded FAS $=0$. We used the distinction between FAS initiation before pregnancy and FAS initiation in the first trimester for a sensitivity analysis but principally reported on results regarding FAS before or during the first 3 months of pregnancy. The variable FAS does not include information on the dose of folic acid taken, nor the frequency or regularity of intake.

We used a range of measures related to the migration status to explore the relationship between migration profiles and FAS: 
- Migration background is determined using the country of birth, rather than nationality, in line with expert recommendations for the operationalisation of migration background in research in Germany ${ }^{(23)}$. Women were categorised as follows: first generation (women born abroad from parents born abroad), second generation (women born in Germany from parents both born abroad), third generation (women born in Germany from parents born in Germany but whose mother tongue is not German) and no migration background. Women born in Germany with only one parent who immigrated were considered as without migration background ${ }^{(23)}$. Second- and third-generation women were pooled together in the analysis, considering the very small number of third-generation women in the sample $(n 4)$.

- We used Turkey as country of origin to single out first- or second-/third-generation women who were born or whose ascendants were born in Turkey. The largest group with a migration background in term of country of origin in our cohort is indeed, similar to what can be observed in Bielefeld ${ }^{(21)}$ and in the general population in Germany ${ }^{(24)}$, the women originally from Turkey.

- Variables relating to language: self-reported German fluency, measured through being a native German speaker ('is German your native language?' a.yes; b.yes, along with another language; c.no; re-categorised as yes (a and b)/no), as well as mention of communication problems during antenatal care (a. often; b. sometimes; c. not very often; $d$. never; re-categorised as yes $(\mathrm{a}, \mathrm{b}, \mathrm{c}) /$ no) was also taken into account. Both language questions have been adapted from the Helius study on ethnicity and health inequalities (the Netherlands) ${ }^{(25)}$.

- Short length of stay in the country of reception refers to women who have lived in Germany for less than 5 years.

Independently and in relation to migration-related variables, we sought to understand the role of formal education. Formal education levels are based on standard education categories of the national statistics office ${ }^{(26)}$ and broken down into three categories. For each category, the maximum formal education attainment was respectively (i) completing high school, (ii) an additional vocational degree, and (iii) a bachelor's degree or equivalent and above.

An important variable was the fact to have a 'planned pregnancy' or not (yes/no), which is one of the main determinants of $\mathrm{FAS}^{(8)}$.

\section{Covariates}

In line with many studies (e.g. ${ }^{(16,17)}$ ), we controlled for the covariates age and parity in our models. Evidence from the Generation R study (the Netherlands), a large prospective cohort study suggests a positive association between age and FAS and a negative association between parity and $\mathrm{FAS}^{(18)}$. A recent, large, population-based study focusing on parity as a determinant of FAS in Israel also found a negative association between parity and dose of FAS purchased prior to child birth ${ }^{(27)}$. We therefore decided to exploratively include these variables as control variables in our models. We used age as a continuous variable rather than age categories and primiparity (being a primipara (yes/no)) rather than number of previous pregnancies due to the relatively small size of our sample.

\section{Analysis}

We estimated the association between potential determinants of FAS and FAS in logistic regressions, calculating first unadjusted OR for each variable of interest described above and then adjusted OR to control for possible confounders. To further explore the interaction between migration background and formal education, we also included an interaction term (migration backgroundxformal education level) in the model. We then stratified the data and look separately at the women without and with migration background in order to (1) investigate the influence of pregnancy planning and formal education in each group specifically and (2) assess the potential influence of migration-related factors (other than migration background) among the women with migration background. Last, we investigated country or region of origins (e.g. originally from Turkey) as determinants of FAS, irrespective of migration background.

In sensitivity analyses, we focused on two types of temporalities, namely if the time at which the women answered the questionnaire (in the last pregnancy trimester or up to 8 weeks postpartum) had an influence on FAS, and if the determinants of FAS differed when looking only at FAS initiation before pregnancy (as opposed to in the first trimester) as an outcome.

Last, we ran a mediation model to refine our understanding of the relation between FAS (=outcome), planned pregnancy (=mediator) and socio-economic status (i.e. formal education, migration background).

The significance level was set at $P<0 \cdot 05$. Descriptive statistics and logistic regression analyses were performed with SAS V9.4. The mediation model was implemented in Stata 16 using the Hicks and Tingley (2011) approach $^{(28)}$.

\section{Results}

\section{Description of the sample}

Data from 947 participants were available for the analysis due to missing values in the variables of interest (e.g. 20 missing values for formal education level, see Supplementary material, Figure A). Characteristics of the participants for each migration background category are presented in Table 1. Overall $83.3 \%(n$ 789) of the women reported taking FAS at any time before or during the first trimester of pregnancy (v. $77.3 \%$ among first-generation migrants), and $47.4 \%$ ( $n$ 449) started before the pregnancy (v.32.6\% among first-generation migrants only). Among the $78.8 \%$ ( $n$ 746) 
Table 1 Main characteristics of the women included in the analysis ( $n$ 947) by migration background, Bielefeld 2013-2016

\begin{tabular}{|c|c|c|c|c|c|c|c|c|}
\hline & \multicolumn{2}{|c|}{ Whole sample } & \multicolumn{2}{|c|}{$\begin{array}{l}\text { Women without } \\
\text { migration } \\
\text { background }\end{array}$} & \multicolumn{2}{|c|}{$\begin{array}{l}\text { Second-/third- } \\
\text { generation } \\
\text { women }\end{array}$} & \multicolumn{2}{|c|}{$\begin{array}{l}\text { First-generation } \\
\text { migrants }\end{array}$} \\
\hline & Mean & SD & Mean & SD & Mean & SD & Mean & SD \\
\hline \multirow[t]{2}{*}{ Age } & 31.5 & 4.9 & $32 \cdot 1$ & 4.6 & $30 \cdot 2$ & $5 \cdot 0$ & $30 \cdot 8$ & $5 \cdot 2$ \\
\hline & $n$ & $\%$ & $n$ & $\%$ & $n$ & $\%$ & $n$ & $\%$ \\
\hline \multicolumn{9}{|l|}{ FAS } \\
\hline No & 158 & $16 \cdot 7$ & 87 & $14 \cdot 5$ & 16 & $15 \cdot 4$ & 55 & $22 \cdot 7$ \\
\hline Initiation before pregnancy & 449 & $47 \cdot 4$ & 324 & 53.9 & 46 & $44 \cdot 2$ & 79 & $32 \cdot 6$ \\
\hline Initiation in the first trimester & 340 & 35.9 & 190 & $31 \cdot 6$ & 42 & $40 \cdot 4$ & 108 & 44.6 \\
\hline \multicolumn{9}{|l|}{ Planned pregnancy } \\
\hline Yes & 746 & $78 \cdot 8$ & 495 & $82 \cdot 4$ & 73 & $70 \cdot 2$ & 178 & $73 \cdot 6$ \\
\hline No & 201 & $21 \cdot 2$ & 106 & $17 \cdot 6$ & 31 & $29 \cdot 8$ & 64 & $26 \cdot 4$ \\
\hline Primiparity & & & & & & 0.0 & & \\
\hline Yes & 366 & 38.6 & 263 & 43.8 & 33 & $31 \cdot 7$ & 70 & 28.9 \\
\hline No & 581 & 61.4 & 338 & $56 \cdot 2$ & 71 & $68 \cdot 3$ & 172 & $71 \cdot 1$ \\
\hline \multicolumn{9}{|l|}{ Formal education level } \\
\hline High school & 137 & $14 \cdot 5$ & 55 & $9 \cdot 2$ & 24 & $23 \cdot 1$ & 58 & $24 \cdot 0$ \\
\hline Higher technical/vocational education & 323 & $34 \cdot 1$ & 184 & $30 \cdot 6$ & 46 & $44 \cdot 2$ & 93 & 38.4 \\
\hline $\begin{array}{l}\text { Higher education (bachelor's degree } \\
\text { or above) }\end{array}$ & 487 & 51.4 & 362 & $60 \cdot 2$ & 34 & $32 \cdot 7$ & 91 & $37 \cdot 6$ \\
\hline \multicolumn{9}{|l|}{ Length of stay $<5$ years } \\
\hline Yes & 27 & $2 \cdot 8$ & 0 & 0.0 & 0 & 0.0 & 27 & $11 \cdot 2$ \\
\hline No & 920 & $97 \cdot 2$ & 601 & $100 \cdot 0$ & 104 & $100 \cdot 0$ & 215 & $88 \cdot 8$ \\
\hline \multicolumn{9}{|l|}{ Native German speaker } \\
\hline Yes & 754 & $79 \cdot 6$ & 601 & $100 \cdot 0$ & 64 & $61 \cdot 5$ & 89 & $36 \cdot 8$ \\
\hline No & 193 & $20 \cdot 4$ & 0 & 0.0 & 40 & 38.5 & 153 & $63 \cdot 2$ \\
\hline \multicolumn{9}{|c|}{ Understanding problem during antenatal care appointments } \\
\hline Yes & 22 & $2 \cdot 3$ & 0 & 0.0 & 1 & 1.0 & 21 & $8 \cdot 7$ \\
\hline No & 925 & $97 \cdot 7$ & 601 & $100 \cdot 0$ & 103 & $99 \cdot 0$ & 221 & $91 \cdot 3$ \\
\hline \multicolumn{9}{|l|}{ Time at which the survey was conducted } \\
\hline Last pregnancy trimester & 300 & 31.7 & 228 & 37.9 & 29 & $27 \cdot 9$ & 43 & $17 \cdot 8$ \\
\hline Within 8 weeks of giving birth & 647 & $68 \cdot 3$ & 373 & $62 \cdot 1$ & 75 & $72 \cdot 1$ & 199 & $82 \cdot 2$ \\
\hline
\end{tabular}

Table 2 Country or region of origin of women with migration background in the whole sample ( $n$ 356), Bielefeld $2013-2016$

\begin{tabular}{|c|c|c|c|c|c|c|}
\hline & \multicolumn{2}{|c|}{$\begin{array}{l}\text { All migration } \\
\text { backgrounds }\end{array}$} & \multicolumn{2}{|c|}{$\begin{array}{l}\text { First-generation } \\
\text { migrants }\end{array}$} & \multicolumn{2}{|c|}{$\begin{array}{l}\text { Second-/third- } \\
\text { generation women }\end{array}$} \\
\hline & $n$ & $\%$ & $n$ & $\%$ & $n$ & $\%$ \\
\hline Turkey & 97 & $27 \cdot 2$ & 42 & $16 \cdot 8$ & 55 & 51.9 \\
\hline Aussiedler (Eastern Europe, with special status) & 97 & $27 \cdot 2$ & 79 & 31.6 & 18 & $17 \cdot 0$ \\
\hline $\begin{array}{l}\text { Eastern Europe (including Russia, excluding } \\
\text { Aussiedler) }\end{array}$ & 65 & $18 \cdot 3$ & 59 & 23.6 & 6 & 5.7 \\
\hline Central Asia & 17 & $4 \cdot 8$ & 15 & 6 & 2 & 1.9 \\
\hline Ex-Yugoslavia & 14 & 3.9 & 7 & $2 \cdot 8$ & 7 & $6 \cdot 6$ \\
\hline $\begin{array}{l}\text { Western, Northern and Southern Europe } \\
\text { (outside Ex-Yugoslavia) }\end{array}$ & 13 & 3.7 & 10 & 4 & 3 & $2 \cdot 8$ \\
\hline South and East Asia & 13 & 3.7 & 11 & 4.4 & 2 & 1.9 \\
\hline Africa & 12 & 3.4 & 9 & $3 \cdot 6$ & 3 & $2 \cdot 8$ \\
\hline America & 10 & $2 \cdot 8$ & 9 & 3.6 & 1 & 0.9 \\
\hline Middle East & 10 & $2 \cdot 8$ & 8 & 3.2 & 2 & 1.9 \\
\hline Mixed & 7 & $2 \cdot 0$ & 1 & 0.4 & 6 & $5 \cdot 7$ \\
\hline Unknown & 1 & 0.3 & 0 & 0 & 1 & 0.9 \\
\hline Total & 356 & $100 \cdot 0$ & 250 & $100 \cdot 0$ & 106 & $100 \cdot 0$ \\
\hline
\end{tabular}

of women who had planned their pregnancies, FAS was higher, at $87.9 \%$. The highest proportion of planned pregnancies was to be found among women without migration background ( $82 \cdot 4 \%)$. Women without migration background represented about two-thirds of the sample (63.5\%; $n$ 601), second-/third-generation women and first-generation migrant women, respectively, made up $11 \%$ ( $n$ 104) and 25.5\% ( $n$ 242) of the sample. Twentyseven women had lived in Germany for less than 5 years. Most of the women reported to be native German speakers (79.6\%), and only $2.3 \%$ mentioned that language was a problem during antenatal care appointments. Just over 
Table 3 Unadjusted and adjusted OR (aOR) of taking folic acid supplement before or during pregnancy ( $n$ 947), Bielefeld 2013-2016

\begin{tabular}{|c|c|c|c|c|c|c|c|}
\hline Main effect & $\begin{array}{c}\text { Unadjusted } \\
\text { OR } \\
\text { (unOR) }\end{array}$ & \multicolumn{2}{|c|}{$95 \% \mathrm{Cl}$} & \multirow{2}{*}{$\frac{P \text {-value }}{0.009}$} & \multirow{2}{*}{$\frac{\mathrm{aOR}}{1.01}$} & $95 \% \mathrm{Cl}$ & \multirow{2}{*}{$\frac{P \text {-value }}{0.62}$} \\
\hline Age ( $n$ 947) & 1.05 & 1.01 & 1.09 & & & $0.97 \quad 1.05$ & \\
\hline Primipara $(n 366)($ ref $=$ no, $n 581)$ & 1.04 & 0.77 & 1.57 & 0.583 & 0.94 & $0.64 \quad 1.39$ & 0.762 \\
\hline $\begin{array}{l}\text { Did not plan the pregnancy }(n 201)(\text { ref }=\text { planned the } \\
\text { pregnancy } n 746)\end{array}$ & 0.27 & 0.19 & 0.39 & $<0.0001$ & 0.33 & $0.22 \quad 0.49$ & $<0.0001$ \\
\hline \multicolumn{8}{|c|}{ Formal education level (ref $=$ bachelor's degree (or equivalent) and above, $n$ 487) } \\
\hline High school (n 137) & 0.27 & 0.17 & 0.44 & $<0.0001$ & 0.46 & $0.27 \quad 0.79$ & 0.005 \\
\hline Vocational training/diploma ( $n$ 323) & 0.45 & 0.31 & 0.68 & 0.0001 & 0.52 & $0.34 \quad 0.80$ & 0.003 \\
\hline \multicolumn{8}{|l|}{ Migration status (ref $=$ no migration background, $n 601$ ) } \\
\hline Second-/third-generation woman (n 104) & $1 \cdot 11$ & 0.63 & 1.95 & 0.707 & $1 \cdot 75$ & $0.81 \quad 3.79$ & $0 \cdot 153$ \\
\hline First-generation migrant (n 242) & 0.58 & 0.40 & 0.84 & 0.004 & 0.91 & 0.521 .61 & 0.750 \\
\hline Not native German speaker ( $n$ 193) (ref = native speaker, $n$ 754) & 0.56 & 0.38 & 0.82 & 0.003 & 0.81 & $0.44 \quad 1.49$ & 0.501 \\
\hline $\begin{array}{l}\text { Had understanding problem during antenatal care appointments } \\
\quad(n \text { 22) (ref = no problem } n \text { 925) }\end{array}$ & 0.42 & 0.17 & 1.04 & 0.061 & 0.89 & $0.29 \quad 2.73$ & 0.845 \\
\hline Originally from Turkey ( $n$ 96) (ref = not from Turkey, $n$ 851) & 0.56 & 0.34 & 0.92 & 0.023 & 0.73 & $0.37 \quad 1.42$ & 0.353 \\
\hline $\begin{array}{l}\text { In Germany since }<5 \text { years }(n 27) \text { (ref }=\text { born in Germany or in } \\
\text { Germany }>5 \text { years, } n \text { 920) }\end{array}$ & 0.46 & 0.20 & 1.08 & 0.007 & 0.88 & 0.312 .48 & 0.806 \\
\hline
\end{tabular}

$50 \%$ of the women had at least a bachelor's degree $(v$. fewer than $40 \%$ in both groups with migration background).

Table 2 shows the country or region of origin of the women with a migration background. About $10 \%$ ( $n$ 97) of the sample were originally from Turkey, and the same proportion were so-called 'resettlers' (Aussiedler in German, i.e. ethnic Germans who returned from former Eastern Block countries after the collapse of the Soviet Union ${ }^{(29)}$ ). Migrants coming from Eastern Europe (including those with Aussiedler status) constituted the majority of the firstgeneration migrants, and women of Turkish origin the majority of the second-/third-generation women.

\section{Multivariate regression analyses}

Unadjusted OR (Table 3) consistently showed significantly different proportions of FAS among women with different migration histories: first-generation migrant women, women with language issues, whose native language was not German, who had migrated more recently, and who were originally from Turkey were all significantly less likely to take FAS before or during pregnancy.

In the multivariate logistic regression, no marker of migration was significantly associated with FAS anymore (Table 3).

The main factors negatively affecting FAS were the two lower categories of formal education attainment (respectively adjusted OR (aOR): 0.46; CI $0.27-0.79$ and aOR: 0.52; CI 0.34-0.80) compared to a higher formal education attainment. Logically and as expected, having had an unplanned pregnancy showed one of the strongest negative associations with FAS (aOR: 0.33; CI 0.22-0.49).

We also ran models including income as an additional independent variable and measure of socio-economic status in addition to formal education and instead of formal education. In both cases, we found no significant association between income and FAS (results not shown).

When introducing an interaction term for the variables formal education and migration background, results remained unchanged and the interaction estimates were not statistically significant (Supplementary material, Table A). Separate multivariate logistic regression models for women without migration background on the one hand, and women with migration background on the other yielded similar results (Supplementary material, Tables B and C). In both groups, only formal education levels and planning the pregnancy were associated with FAS. This means that even among women with a migration background only, the migration-related variables had no influence on FAS. Last, when not taking into account migration background, but instead focusing on country or region of origin (Turkey, Aussiedler and Other), we found again no statistically significant association with FAS (Supplementary material, Table D).

Sensitivity analyses with regard to timing of FAS (Supplementary material, Table E) showed patterns similar to previous models - although logically, having an unplanned pregnancy decreased even more the chances of FAS before pregnancy (aOR: 0.11; CI 0.07-0.18). The timing of the baseline interview (Supplementary material, Table F) was not significantly associated with FAS.

Considering the role of formal education and planned pregnancy and the fact that they are often linked (see Background), we built a mediation model to investigate whether and to which extent the effect of formal education on FAS is mediated by the fact to have an unplanned pregnancy. We found that unplanned pregnancy contributed to $20 \%$ of the association between formal education and FAS, highlighting the relationship between formal education and planned pregnancy, but also the role of formal education as a potential determinant of FAS, independently of the timing of pregnancy. Since the correlation between FAS and migration background was not statistically significant in the multivariate logistic regression, we did not build a mediation model with the migration background variable. 
Table 4 Main reasons why participants did not take folic acid supplementation ( $n$ 108) by migration background, Bielefeld $2013-2016$

\begin{tabular}{|c|c|c|c|c|c|c|c|}
\hline \multirow[b]{2}{*}{ Reason } & \multirow{2}{*}{$\frac{\text { Total }}{n}$} & \multicolumn{2}{|c|}{$\begin{array}{c}\text { Women without } \\
\text { migration } \\
\text { background }\end{array}$} & \multicolumn{2}{|c|}{$\begin{array}{l}\text { First-generation } \\
\text { migrants }\end{array}$} & \multicolumn{2}{|c|}{$\begin{array}{l}\text { Second-/third- } \\
\text { generation } \\
\text { women }\end{array}$} \\
\hline & & $n$ & $\%$ & $n$ & $\%$ & $n$ & $\%$ \\
\hline Was pregnant faster than planned & 84 & 56 & $91 \cdot 8$ & 21 & $61 \cdot 8$ & 7 & $87 \cdot 5$ \\
\hline Did not know about FAS & 10 & 5 & 8.2 & 5 & 14.7 & 0 & 0.0 \\
\hline $\begin{array}{l}\text { Knew about FAS but decided } \\
\text { not to take it }\end{array}$ & 8 & 0 & $0 \cdot 0$ & 8 & $23 \cdot 5$ & 1 & $12 \cdot 5$ \\
\hline Total & 113 & 61 & $100 \cdot 0$ & 34 & $100 \cdot 0$ & 8 & $100 \cdot 0$ \\
\hline
\end{tabular}

FAS, folic acid supplementation.

\section{Reasons for not taking folic acid supplementation}

Table 4 shows the main reasons reported by participants when asked why they did not take FAS before or during their pregnancy, by migration background. Out of 158 participants who did not use supplements, 108 gave a reason for doing so. The most frequently cited reason was that the woman became pregnant earlier than expected, not leaving time to start supplementation as indicated. Apart from the planning reason, the two other reasons were lack of knowledge or a conscious decision not to take supplementation (e.g. because the pregnant women felt it was not needed nor a priority). Those two last reasons were most prevalent among first-generation migrants (14.7\% and $23.5 \%)$. The small numbers limited further analyses. However, we grouped lack of knowledge and decision not to take FAS in a binary outcome and looked at the effect of first-generation migrant status, formal education level and planning the pregnancy in a multivariate logistic regression. As a result, we found a higher likelihood of not knowing about FAS/deciding against FAS among first-generation migrants (aOR: 6.54; CI 2.26-18.93), and among women with the lowest formal education level (aOR: 3·72; CI 0.97-14.18).

\section{Discussion}

\section{Main implications of the results}

In unadjusted regression analyses, markers of migration (e.g. migration background, language and length of stay) showed a statistically significant association with a lower likelihood of FAS for women with a migration background. These results did not hold in multivariate models, where a lower level of formal education and an unplanned pregnancy were the main explanatory variables. Reasons given by women for not taking FAS were not having planned the pregnancy, not knowing about FAS or having decided not to take it. The two latter reasons seemed to be more prevalent among first-generation migrants and women with the lowest formal education level.

The fact that migration-related variables showed no significant association with FAS is, to some extent, different from some of the international evidence which has highlighted the role of migration status and ethnicity (e.g. ${ }^{(9,11,19)}$ ) on FAS. However, it also shows how important it is to take into account formal education when researching the health of populations with a migration background, and that formal education, rather than migration background, might be the key to differences in behaviours - calling for more socio-economic equality in the migrants' country of reception. Some of these results may be also partly explained by the particular characteristics of our sample, which showed in comparison to the general population a relatively high level of formal education. This was also the case among the women with a migration background. In any case, our findings highlight differences in consumption of FAS across different population subgroups and the vulnerability accumulated by some women. In particular, our analysis of the reasons for which women were not taking FAS tends to suggest that specific knowledge and understanding challenges around the usefulness and benefits of FAS should be tackled, especially among migrants and women with lower formal education level.

With regard to the role of formal education, our findings are in line with the literature on FAS before and during pregnancy ${ }^{(9-15)}$. They underline the role of formal education in adopting healthy behaviours in the perinatal period and are a stark reminder of the importance of health literacy. Understood as 'a set of skills that are required to function well in the health care or public health setting', it is considered to be a significant social determinant of health which cannot indeed be disentangled from education ${ }^{(30,31)}$. With regard to prenatal health, findings from a recent review showed that low health literacy is associated with unplanned pregnancy, non-utilisation of supplements during pregnancy and the perception that taking medicine carries some risk ${ }^{(32)}$. Although this resonate with our findings, including the reasons for not taking FAS, our results additionally underline that formal education and planned pregnancy influence independently folic acid intake supplementation. This calls for different strategies to counter low supplementation rates: those addressing the social determinants of health (i.e. education) and those more focused on increasing knowledge of FAS in reproductive health and family planning services. The latter could include taking more systematically advantage of women's 
use of gynaecological services from adolescence to adulthood to raise awareness on FAS among all girls and women $^{(33,34)}$, independently of their sexual activity or plans to conceive.

The absence of knowledge of FAS, the reluctance to take many tablets and pills during pregnancy, or beliefs that a balanced diet can prevent low folate levels, could be better tackled with folate fortification rather than relying on the women's initiative to take tablets. Food fortification, whose German advocates are relentlessly calling for ${ }^{(4,7)}$, remains despite some shortcomings (e.g. vitamin $\mathrm{B}_{12}$ masking ${ }^{(35)}$ ) the most successful and most equitable intervention to tackle folate deficiency ${ }^{(36)}$, while behavioural interventions to increase individual supplementation are proven ineffective or poorly documented ${ }^{(37)}$. This supports the ideas that interventions aiming to address low rates of FAS should go beyond the focus on individual responsibility and individual behaviours and address more broadly the structural determinants of health. Additionally, the tricky timing of FAS (which has to start before the pregnancy, before even the plan for a pregnancy) calls for more innovative solutions which do not only target women of reproductive age, including, as suggested by a recent review, population-wide social movements and advocacy coalitions ${ }^{(38)}$. These would benefit not only women who did not plan to take FAS, but also those who would have started FAS too late in the pregnancy.

Last, another potential socio-economic determinant to investigate pertains to the cost of FAS: although the cost of the tablets can be covered by health insurance schemes in certain cases, FAS is usually purchased without prescription and paid for by the women. Depending on where it is purchased and the brand, it can cost anything between $7 €$ and $30 €$ for 3 months worth of tablets. Although cost was not mentioned as a deterrent to intake in our study, the willingness to pay of those who are fully informed of the benefits and those who are not could be investigated.

\section{Strengths and limitations}

A couple of limitations of our study pertains to data collection and measurement. For example, we did not measure actual intake of FAS nor compliance with a specific supplementation regimen. When a participant said she was taking folic acid supplement, we did not ask for more details, e.g. if they took it every day, what was the dosing, if they often missed a tablet, etc. There was also a possibility of a recall bias or confusion as to whether they took FAS because it can be included in multivitamin tablets. However, the design of our data collection instrument aimed at mitigating this risk: in the questionnaire we asked first about any supplements and then specifically about FAS. In terms of timing of the interviews, no women were interviewed before the 12 th week of pregnancy, but $2 / 3$ were interviewed shortly and up to 8 weeks after giving birth. For those interviewed postpartum, the recall bias might be more important than for the other participants. It is to be noted, however, that we did not find differences in FAS between the two groups. With regard to the variable on planned pregnancy, it is of course possible that participants have different understandings of what is a planned or unplanned pregnancy ${ }^{(39)}$, something that we cannot account for in our quantitative analyses.

Last, one cannot exclude that our relatively small sample size may have limited the statistical power of subgroup analyses and therefore failed to capture the significance of some of the correlations between migration variables and FAS.

An undeniable strength of our study is the inclusion of a large proportion of participants with a migration background. This group also shows variance in formal education level, which is not so common in studies with a focus on migrants. It allows to disentangle the migration-related effects from the education effects on health outcomes.

\section{Conclusion}

Health practitioners may be inclined to see migrant women as an inherently at-risk group for failed intake of FAS. However, they need to do so in a differentiated way: our findings confirm the well-known observation that it is primarily women who did not plan their pregnancy, and women of lower formal education level, who are at risk. Migrant status is merely a marker of these known risks, but conveys little (if any) additional risk of its own. Different public health strategies to counter low supplementation rates should be supported: those addressing the social determinants of health (i.e. education) and those more focused on increasing knowledge of FAS in family planning and reproductive health services.

\section{Acknowledgements}

The authors thank all the women who agreed to participate in this study, as well as the hospitals and practices who collaborated with them. The authors would also like to thank Renata Hoffman, Emine Ergin, Jutta Schmitz, Guelseren Yazaydin and Ilknur Oezer Erdogdu for their contribution to data collection and for providing administrative support during the research project.

\section{Financial Support}

The study was funded by a grant from Germany's Bundesministerium fuer Bildung und Forschung (BMBF grant 01ER1202; PIs: JS, OR, AL, CM). It is now continued by the Junior Research Group Gender Epidemiology funded by Bielefeld University (PI: CM).

\section{Conflict of Interest}

The authors declare no conflict of interest. 


\section{Authorship}

$\mathrm{CM}$ conceived the research question, conducted the analyses and wrote the first draft of the paper with input from OR. $\mathrm{AL}, \mathrm{IM}-\mathrm{D}$ and $\mathrm{CH}$ helped to develope the research question in the early stages of the paper, JB contributed to the analyses, and JS and OR conceived the study. All authors read, contributed to and approved the final manuscript.

\section{Ethics of Human Subject Participation}

This study was conducted according to the guidelines laid down in the Declaration of Helsinki and all procedures involving research study participants were approved by the ethical committee of the Medical Faculty of Muenster University and the Data Protection Board of Bielefeld University. Written informed consent was obtained from all participants.

\section{Availability of Data and Material}

Data are available upon request for on-site analysis due to data protection restrictions. Interested researchers may submit requests to Dr Céline Miani, leader of the BaBi Study, School of Public Health, Bielefeld University. Contact: Universitätsstraße 25, 33615 Bielefeld, Germany. E-mail: celine.miani@uni-bielefeld.de.

\section{Supplementary material}

For supplementary material accompanying this paper visit https://doi.org/10.1017/S1368980021003621

\section{References}

1. Koletzko B, Bauer CP, Bung P et al. (2013) German national consensus recommendations on nutrition and lifestyle in pregnancy by the 'Healthy Start - Young Family Network'. Ann Nutr Metab 63, 311-322.

2. De-Regil LM, Peña-Rosas JP, Fernández-Gaxiola AC et al. (2015) Effects and safety of periconceptional oral folate supplementation for preventing birth defects. Cochrane Database Syst Rev, Issue 12. Art. No.: CD007950. doi: 10.1002/14651858.CD007950.pub3 (accessed September 2021).

3. Franke C, Verwied-Jorky S, Campoy C et al. (2008) Dietary intake of natural sources of docosahexaenoic acid and folate in pregnant women of three European cohorts. Ann Nutr Metab 53, 167-174.

4. Herrmann W \& Obeid R (2011) The mandatory fortification of staple foods with folic acid: a current controversy in Germany. Dtsch Ärztebl Int 108, 249-254.

5. Kirschner W (2003) Ernährungssituation und Ernährungswissen bei Schwangeren-Eine Analyse auf der Grundlage des Vorsorgeprogramms BabyCare in der Schwangerschaft. Ernäbrung Med 18, 71-76.
6. Becker S, Schmid D, Amann-Gassner U et al. (2011) Verwendung von Nährstoffsupplementen vor und während der Schwangerschaft. Ernäbrungs Umschau 58, 36-41.

7. Wegner C, Kancherla V, Lux A et al. (2020) Periconceptional folic acid supplement use among women of reproductive age and its determinants in central rural Germany: results from a cross sectional study. Birth Defects Res 112, 1057-1066.

8. Mannien J, de Jonge A, Cornel MC et al. (2014) Factors associated with not using folic acid supplements preconceptionally. Public Health Nutr 17, 2344-2350.

9. Kinnunen TI, Sletner L, Sommer C et al. (2017) Ethnic differences in folic acid supplement use in a populationbased cohort of pregnant women in Norway. BMC Pregnancy Childbirth 17, 143.

10. Koken GN, Derbent AU, Erol O et al. (2013) Awareness and use of folic acid among reproductive age and pregnant women. J Turk Ger Gynecol Assoc 14, 87-91.

11. Baraka MA, Steurbaut S, Leemans L et al. (2011) Determinants of folic acid use in a multi-ethnic population of pregnant women: a cross-sectional study. J Perinat Med 39, 685-692.

12. Lawal TA \& Adeleye AO (2014) Determinants of folic acid intake during preconception and in early pregnancy by mothers in Ibadan, Nigeria. Pan Afr Med J 19, 113.

13. Nilsen RM, Leoncini E, Gastaldi P et al. (2016) Prevalence and determinants of preconception folic acid use: an Italian multicenter survey. Ital J Pediatr 42, 1-10.

14. Birkenberger A, Henrich W \& Chen F (2019) FolsäureEinnahme bei Berliner Frauen in Abhängigkeit vom sozioökonomischen Status. Zeitschrift für Geburtshilfe und Neonatologie 223, 213-220.

15. Teixeira JA, Castro TG, Wall CR et al. (2018) Determinants of folic acid supplement use outside national recommendations for pregnant women: results from the Growing Up in New Zealand cohort study. Public Health Nutr 21, 2183-2192.

16. Tort J, Lelong N, Prunet C et al. (2013) Maternal and health care determinants of preconceptional use of folic acid supplementation in France: results from the 2010 National Perinatal Survey. BJOG 120, 1661-1667.

17. van Eijsden M, van der Wal MF \& Bonsel GJ (2006) Folic acid knowledge and use in a multi-ethnic pregnancy cohort: the role of language proficiency. BJOG 113, 1446-1451.

18. Timmermans S, Jaddoe VW, Mackenbach JP et al. (2008) Determinants of folic acid use in early pregnancy in a multi-ethnic urban population in The Netherlands: the Generation R study. Prev Med 47, 427-432.

19. Chote AA, Koopmans GT, de Groot CJ et al. (2014) Differences in timely antenatal care between first and second-generation migrants in the Netherlands. J Immigr Minor Health 16, 631-637.

20. Palmer R, Layte R \& Kearney J (2019) The maternal health behaviours of non-Irish nationals during pregnancy and the effect of time living in Ireland. Public Health 170, 95-102.

21. Ministerium fuer Kinder Familie Fluechtlinge und Integration des Landes NordRhein-Westphalen (2018) Integrationsprofil Bielefeld. Daten zu Zuwanderung und Integration. Ausgabe 2018. http://www.integrationsmonitoring.nrw.de/integrations berichterstattung_nrw/Integration_kommunal/Integrations profile/Integrationsprofile-Bielefeld.pdf (accessed 05 February 2020).

22. Spallek J, Grosser A, Höller-Holtrichter C et al. (2017) Early childhood health in Bielefeld, Germany (BaBi study): study protocol of a social-epidemiological birth cohort. BMJ Open 7, e018398.

23. Schenk L, Bau AM, Borde T et al. (2006) A basic set of indicators for mapping migrant status. Recommendations for epidemiological practice. Bundesgesundheitsblatt Gesundheitsforschung Gesundheitsschutz 49, 853-860. 
24. Statistisches Bundesamt (Destatis) (2018) Bevölkerung und Erwerbstätigkeit: Bevölkerung mit Migrationshintergrund Ergebnisse des Mikrozensus 2017. https://www.destatis.de/ DE/Themen/Gesellschaft-Umwelt/Bevoelkerung/MigrationIntegration/Publikationen/Downloads-Migration/migration shintergrund-2010220177004.pdf?_blob=publicationFile\& $\mathrm{v}=4$ (accessed 14 February 2020).

25. Helius (2012) Aim of the Study. https://www.heliusstudy.nl/en/ over-helius/doel-van-het-onderzoek/ (accessed 12 May 2021).

26. Statistisches Bundesamt (Destatis) (2010) Methoden: Demographische Standards. https://www.destatis.de/DE/ Methoden/Demografische-Regionale-Standards/textbausteindemografische-standards.html (accessed 12 May 2021).

27. Moser SS, Rabinovitch M, Rotem R et al. (2019) Parity and the use of folic acid supplementation during pregnancy. BMJ Nutr Prev Health 2, 30.

28. Hicks R \& Tingley D (2011) Causal mediation analysis. Stata J 11, 605-619.

29. BMI (Bundesministerium des Innern fBuH Lexicon). Aussiedler. https://www.bmi.bund.de/DE/service/lexikon/ functions/bmi-lexikon.html?cms_lv3=9397790\&cms_lv2= 9391092\#doc9397790 (accessed 12 May 2021).

30. Jansen T, Rademakers J, Waverijn G et al. (2018) The role of health literacy in explaining the association between educational attainment and the use of out-of-hours primary care services in chronically ill people: a survey study. $B M C$ Health Serv Res 18, 394-394.

31. Berkman N, Sheridan S, Donahue K et al. (2011) Low health literacy and health out-comes: an updated systematic review. Ann Intern Med 155, 97-107.
32. Kilfoyle KA, Vitko M, O'Conor R et al. (2016) Health literacy and Women's reproductive health: a systematic review. $J$ Women's Health 25, 1237-1255.

33. Hanson MA, Bardsley A, De-Regil LM et al. (2015) The International Federation of Gynecology and Obstetrics (FIGO) recommendations on adolescent, preconception, and maternal nutrition: "Think Nutrition First"\#. Int $J$ Gynecol Obstet 131, S213-S253.

34. Bitzer J, von Stenglin A \& Bannemerschult R (2013) Women's awareness and periconceptional use of folic acid: data from a large European survey. Int J Women's Health $\mathbf{5}$, 201-213.

35. Mills JL, Molloy AM \& Reynolds EH (2018) Do the benefits of folic acid fortification outweigh the risk of masking vitamin B12 deficiency? BMJ 360, k724. doi: 10.1136/ bmj.k724.

36. Teixeira JA, Castro TG, Wall CR et al. (2019) Effects of folic acid food fortification scenarios on the folate intake of a multi-ethnic pregnant population. Public Health Nutr 22, 738-749.

37. Botto LD, Lisi A, Bower C et al. (2006) Trends of selected malformations in relation to folic acid recommendations and fortification: an international assessment. Birth Defects Res A Clin Mol Teratol 76, 693-705.

38. Barker M, Dombrowski SU, Colbourn T et al. (2018) Intervention strategies to improve nutrition and health behaviours before conception. Lancet 391, 1853-1864.

39. Arteaga S, Caton L \& Gomez AM (2019) Planned, unplanned and in-between: the meaning and context of pregnancy planning for young people. Contraception 99, 16-21. 